\title{
СИСТЕМНЫЕ ЗАКОНОМЕРНОСТИ ФОРМИРОВАНИЯ РОССИЙСКОЙ МОДЕЛИ ИНДУСТРИАЛЬНОГО РАЗВИТИЯ СОЦИАЛЬНО-ПРОИЗВОДСТВЕННЫХ СИСТЕМ С ИСПОЛЬЗОВАНИЕМ ИНТЕГРИРОВАННОГО ТЕХНОЛОГИЧЕСКОГО МЕНЕДЖМЕНТА
}

\author{
(c) 2019 Глисин Алексей Федорович \\ кандидат экономических наук, доцент Департамента Корпоративных финансов и корпоративного \\ управления \\ Финансовый университет при Правительстве Российской Федерации, Россия, Москва \\ E-mail: alglisin@gmail.com
}

(c) 2019 Малышев Николай Иванович

кандидат экономических наук, доцент

АНО ДПО Научно-Образовательный Центр «Импульс»

E-mail:nimal1907@mail.ru

\begin{abstract}
В статье анализируются вопросы управления с точки зрения новых тенденций, возникающих при переходе экономики к «Индустрии 4.0» и их взаимосвязь с процессами повышения уровня технологического развития. Рассматриваются возможные варианты и пути модернизации систем менеджмента отечественных предприятий и организаций на новой современной теоретической основе и практическом опыте стран с развитой рыночной экономикой. Прослеживаются основные концептуальные изменения в системе управленческих знаний и их влияние на процессы инновационного подъема отечественной экономики.
\end{abstract}

Ключевые слова: экономика организации, инновационное развитие, технологическое развитие производства, технологические факторы развития экономики, интегрированный технологический менеджмент.

Рыночная экономика во всем мире постоянно меняется, совершенствуется и развивается. Изменения затрагивают общественные потребности, виды экономической деятельности и их взаимосвязь, прогрессивные технологии и ценности, которые ими создаются. Эти процессы обуславливают пересмотр и переоценку существующих экономических теорий, способствуют возникновению новых. Изменения, происходящие в российской экономике, также находят свое отражение в системе научных знаний общества, качестве его информированности о происходящих процессах, событиях, явлениях, используемом научно-технологическом потенциале, в системе современного гуманитарного, экономического и технологического образования.

Сложившееся технологическое, а следовательно, и экономическое отставание страны от развитых экономик мира, функционирование в режиме санкций со стороны ряда технологически развитых стран, экономический кризис и его влияние на неустойчивую рыночную среду являются закономерными результатами невостребованности в течении почти четверти века со стороны государственной власти интеллектуального потенциала страны, и, как следствие, фактическим отсутствием в национальной экономике логически построенной и научно аргументированной системы знаний о ее функционировании, внутренних взаимосвязях процессов и явлений, перспективах дальнейшего развития. Естественно, многие руководители не имеют четкого научного представления о том, как должна быть построена экономика организации, сектора экономики, региона, страны в целом, как она должна регулироваться и управляться [1, с. 35].

Результатом реформирования отечественной экономики, как декларировалось в 90-е годы, должно было стать обеспечение социально-экономического и организационно-хозяйственного фундамента для строительства в России мощной индустриальной научно управляемой экономики, способной гарантировать гражданам политические свободы и материальное благополучие, 
а стране в целом - надежную защищенность и способность успешно отстаивать российские национальные интересы на международной арене, не прибегая к военной силе.

Однако на практике эта задача была выполнена лишь частично, ее решение сопровождалось рядом крупных просчетов и потерь, одним из которых было игнорирование создания в России конкурентоспособного сектора высокотехнологичных производств, способного выступать локомотивом устойчивого индустриального развития страны с перспективой завоевания, удержания и расширения экономически и стратегически наиболее благоприятных позиций в международном разделении труда. Игнорирование технологических факторов развития экономики явилось одной из основных причин экономического и социально-политического кризиса страны, который не преодолен и сегодня [2, с. 39]. В результате пренебрежения властными структурами современной экономической теории расширенного воспроизводства с использованием современных кибернетических интеллектуальных систем на практике принимаются нетехнологичные решения без должной экспертной оценки и прогнозирования возможных последствий, совершаются ненужные, а иногда и опасные коррупционные действия, ведущие к значительным потерям всех видов ресурсов, снижению стоимости труда во всех сферах экономической деятельности [7]. Отсутствие на практике современных технологических стандартов управления сдерживает развитие производства на уровне организаций малого и среднего бизнеса, основных источников роста ВВП и экономического развития [3, с. 91].

После целого ряда неудачных экономических реформ, во многом обусловивших кризисные явления российской экономики, наконец, впервые за последние десятилетия в декабре 2016 года была утверждена Стратегия научно-технологического развития России [8], которая сформулировала и утвердила качественно новое направление развития страны - технологическое развитие производства конкурентоспособной продукции всех видов. Стратегия определила в качестве основной цели трансформацию науки и технологий в ключевой фактор развития России, определяющий конкурентоспособность национальной экономики. Отсюда следует, что важнейшие задачи обеспечения конкурентоспособности производства являются задачами технологическими, требующими разработки новых методов, моделей и механизмов технологического развития экономики на всех уровнях народного хозяйства [4, с. 91].

Для реализации стратегии предусматривается консолидация усилий научных и образовательных организаций, промышленных предприятий и находящихся в их распоряжении инструментов исследования, проектирования, моделирования, сертификации и практической реализации прогрессивных системных технологий [9].

В настоящее время мировая экономика перерастает в четвертую промышленную революцию, характеризующуюся сочетанием технологий, размывающих границы между физической, цифровой и биологической сферами...»,- так открыл всемирный экономический форум в Давосе (2016 г.) профессор Клаус Шваб.

Третья (ее можно назвать первой информационной) революция «не вписалась» в советский строй. Не только потому, что громоздкая система планирования по воле руководства страны выбрала ориентиром громадные ЭВМ, «прозевав» персональные компьютеры. Проблема еще и в том, что вся советская система была организована по строго вертикальному принципу, с дозированным доступом к информации, а персональный компьютер - это первый камень в фундаменте принципиально новых горизонтальных связей - основы будущего производства, ну и, конечно, путь к информационной свободе. Можно считать, что третья промышленная революция в Россию была по существу импортирована. И хотя третья индустриальная революция еще далека от завершения, но прогресс, в том числе и в первую очередь благодаря ей, ускоряется.

Четвертая промышленная революция - это будущее, которое уже начинается. Концепция «Индустрия 4.0» неслучайно была выдвинута в Германии. Там поняли, что если не попытаться возглавить движение в будущее можно остаться в прошлом. Немецкая промышленность уже инвестирует 40 миллиардов евро в промышленную интернет-инфраструктуру ежегодно до 2020 года.

Пароль четвертой индустриальной революции - нейрокибернетические интеллектуальные системы (НКИС), которые будут определять социально-технологическое лицо производства будущего. Кибернетические принципы позволя- 
ют предвидеть появление проблем, вероятность развития событий, смоделировать и оценить возможные риски.

У гонки в рамках четвертой индустриальной революции есть и стратегическая цель - кто определит будущие технологические стандарты тот займет место наверху [5, с. 91]. Новая революция означает огромный объем коммуникаций между разными системами, все машины должны говорить на одном языке. Если незаконченный продукт прибудет на машину, которая должна будет его довести до конечного вида, но не сможет считать его чип, производство превратится в хаос. Таким образом, определение общих платформ и языков, на которых будут общаться машины разных корпораций,- не просто техническая задача, это заявка на будущие финансовые сливки [10].

По прогнозу известного технологического футуролога Рэя Курцвейла, который является техническим директором Google, уже к 2020му году персональные компьютеры достигнут вычислительной мощности, сравнимой с человеческим мозгом, а к 2038 году появятся роботизированные люди, продукты «трансгуманистических технологий».

Германия не одинока на маршруте четвертой индустриальной революции. В США в 2014 году был создан некоммерческий консорциум Industrial Internet. В Китае и Южной Корее ведется большая работа по созданию глобальных стандартов и систем, которые позволят сделать производство «умнее». Четвертая индустриальная революция кардинально изменит рынок труда.

Где же в четвертой индустриальной революции место России? Страна отстала, причем именно за постсоветское время, не успев технологически и социально адаптироваться к новым условиям и вызовам.

Ответ Г.О.Грефа на сакраментальное «Что делать?» радикальный: «Изменять все государственные системы России», начиная с модели образования. «Я не верю в науку, которая не связана с практикой и образованием, я не верю в образование, которое не связано с практикой и с наукой, я не верю в бизнес, который не связан ни с наукой, ни с образованием - вот кредо Грефа.

Более развернутую «перекодировку» российского образования предложил Алексей Комиссаров, генеральный директор Фонда развития промышленности. Чтобы построить социально-эффективное будущее страны необходимо:

«1. Запустить программу подготовки детей через специальные уроки технологического предпринимательства и творчества в школах и даже в детских садах, как это сделано в ряде стран Европы. Создать обширную сеть детских технопарков в регионах, систему олимпиад и конкурсов.

2. Максимальное внимание уделить важному сохраненному конкурентному преимуществу России - лучшей в мире математической школе. Надо возрождать и создавать новые специальные физико-математические средние школы, удерживать и максимально стимулировать лучших преподавателей, отбирать и поддерживать талантливых детей. В эпоху тотальной диджитализации планеты специалисты с математическим образованием будут не просто востребованы, возможно, именно они будут создавать новые тренды будущего мира».

Задача научно-технологической стратегии - помочь будущему поколению осмыслить и освоить современные системные технологии для решения проблем развития производства, механизмы воспроизводства научно-технологического потенциала страны, спрогнозировать и спланировать единоесбалансированное технологическое народнохозяйственное пространство. «Рынок,- писал Дж. Стиглиц,- это совокупность механизмов финансирования, проектирования, разработки, реализации и развития инновационных программ, проектов и технологий». Если одного механизма нет, то нельзя говорить о рыночной экономике.

Когда создается любой организм как единая система, должны быть заложены (спроектированы) механизмы его «рождения», обеспечения жизнедеятельности и развития [6, с. 91]. Эти технологические процессы необходимо своевременно и качественно, спрогнозировать, спланировать, спроектировать, организовать их взаимодействие, постоянно поддерживать ресурсами и постоянно технологически развивать.

В известной книге «Выход из кризиса» Э. Деминг в 1992 г. познакомил американцев с собственным видением современного стиля управления - системой «идеального бизнеса», которая позволяет постоянно повышать качество продукции, улучшать системную управляемость фирмой при одновременном снижении затрат. Эти и другие стратегически перспектив- 
ные задачи формирования национальной модели «Индустрия 4.0» являются объектом системы интегрированного технологического менеджмента - парадигмы менеджмента XXI века.

Продолжая тему технологического развития и определения места России в глобальных процессах рождения новой экономической реальности, следует подчеркнуть, что именно предпринимательская интеллектуально-технологическая деятельность выводит на рынок инновации, обеспечивает рождение и развитие новых технологий, способствует появлению новых отраслей промышленности, увеличивает конкуренцию на различных рынках как внутри государства, так и на мировой арене. И в этой связи, как показывают исследования различных зарубежных авторов, именно технологическое предпринимательство дает наибольший социальный и экономический вклад в развитие технологического потенциала стран, что обусловлено быстрым ростом малых инновационных компаний, особенно в высокотехнологичных отраслях.

Известные экономисты Дорф и Байерс определяют технологическое предпринимательство как стиль бизнес-лидерства, включающий в себя определение многообещающих, с техническими средствами высокого уровня, возможностей производства продукции для коммерческого сбыта, накопление ресурсов, таких как талант и капитал, а также управление быстрым ростом и существенными рисками через использование принципиальных навыков принятия решений.

B нашей стране нефтегазовые доходы по прежнему продолжают составлять более поло- вины от всех поступлений федерального бюджета. Однако, уровень технологического предпринимательства остается достаточно низким (по разным данным не более $10 \%$ предприятий малого бизнеса можно отнести к технологическим компаниям), несмотря на то, что Россия занимает примерно пятидесятое место из почти полутора сотен стран по уровню инновационного развития.

Сложившаяся ситуация требует резкого увеличения доли технологического предпринимательства в России. Однако, как в нашей стране, так и в других странах наблюдается недостаток управленческих знаний и опыта у потенциальных технологических предпринимателей, что значительно усложняет процесс реализации проектов, а также требует значительных денежных и временных затрат.

Таким образом, для быстрого и стабильного развития технологического предпринимательства необходимо предоставление образовательной и информационной поддержки со стороны государства и бизнес-сообщества. Так как зачастую у потенциальных технологических предпринимателей отсутствуют навыки ведения собственного бизнеса, каждый университет должен предлагать предпринимательские курсы. Это отличный способ преподать универсальные управленческие навыки, которые включают в себя умение адаптироваться к постоянным изменениям и понимание рыночной конъюнктуры, что, несомненно, приведет к увеличению доли технологического предпринимательства в России.

\section{Библиографический список}

1. Глисин Ф.Ф., Калюжный В.В. Оценка эффективности научной и инновационной деятельности в зарубежных странах и в России // Инновации. - 2015. - № 6. - С. 32-37.

2. Ф.Ф. Глисин, В.В. Калюжный. Прогнозирование показателей научной деятельности // Инновации. - 2014.№ 11(193). - С. 37-44.

3. Концепция технологического развития России: (проект) / В.Н. Брюнин,.В. Хотулев, С.М. Меньшиков, Ф.Ф. Глисин.- М.: АТН РФ, ИТЦ «ИНТЭКС» предприятия «Новинтех-ИНКОР»МЭСИ, МЦТСПО, 1992.- 91 с.

4. Глисин А.Ф. Некоторые особенности развития современной инновационной экономики // Сборник статей международной научно-практической конференции «Актуальные проблемы экономики». Часть 1. Ответственный редактор Сукиасян А.А., Издательство: Аэтерна, Уфа - 2015 - С.92-98.

5. Г. Б. Клейнер. Системная парадигма и системный менеджмент // Российский журнал менеджмента - 2008. № 3, Том 6,- С. 27-50.

6. Малышев Н.И. Шевченко С. С. Системные закономерности и механизмы управления технологическим развитием производственных систем // Управленческие науки в современном мире. - 2016._ № 1. - С. 354357.

7. Итоги МЭФ-2016: экономический курс адекватным не назвал никто!, / [Электронный ресурс].- Режим доступа: http://me-forum.ru/media/news/5635/ 
8. Указ Президента РФ от 01.12.2016 N642 «О Стратегии научно-технологического развития Российской Федерации», / Консультант Плюс, 1992-2017 [Электронный ресурс].- Режим доступа: http://www.consultant.ru/ law/hotdocs/48053.html

9. Результативность научных исследований и разработок: 2017, 2016, 2015, 2014, 2013, / Федеральное государственное бюджетное научное учреждение «Научно-исследовательский институт - Республиканский исследовательский научно-консультационный центр экспертизы» (ФГБНУ НИИ РИНКЦЭ). - М.: ФГБНУ НИИ РИНКЦЭ, 2015. [Электронный ресурс]. - Режим доступа: http://www.csrs.ru/archive/

10. И. Хель, Индустрия 4.0: что такое четвертая промышленная революция? 2015. [Электронный ресурс].- Режим доступа: https://hi-news.ru/business-analitics/industriya-4-0-chto-takoe-chetvertaya-promyshlennayarevolyuciya.html 